\title{
A tale of two risks in the EMU sovereign debt markets
}

\author{
Erdinc Akyildirim ${ }^{\mathrm{a}}$, Duc Khuong Nguyen ${ }^{\mathrm{b}}$, Ahmet Sensoy ${ }^{\mathrm{c}, *, 1}$ \\ a University of Zurich, Department of Banking and Finance, Zurich, Switzerland \\ b IPAG Lab, IPAG Business School, Paris, France \\ ${ }^{\mathrm{c}}$ Bilkent University, Faculty of Business Administration, Ankara 06800, Turkey
}

\section{H I G H L I G H T S}

- Introduce dynamic systematic yield risk (SYR) and liquidity risk (SLR) measures for EMU sovereign bond markets.

- Trend components of SYR and SLR are strongly positively correlated.

- Shocks to the SLR has significant impact on SYR lasting up to 5 days.

- Shocks to the SYR has no significant impact on SLR.

- As of 2018, both SYR and SLR are at their highest levels.

\section{A R T I C L E I N F O}

\section{Article history:}

Received 12 July 2018

Received in revised form 27 August 2018

Accepted 29 August 2018

Available online 1 September 2018

\section{JEL classification:}

G01

G13

G14

Keywords:

European Monetary Union

Sovereign bonds

Systematic risk

Liquidity

\begin{abstract}
A B S T R A C T
We introduce time-varying systematic yield risk (SYR) and systematic liquidity risk (SLR) measures for sovereign bond markets of the major European Monetary Union (EMU) country members. Using daily sovereign bond data, our analysis shows that trend components of both types of risk are strongly positively correlated. Vector auto-regression and generalized impulse response analysis reveal that shocks to the SLR has significant impact on SYR lasting up to 5 days, whereas shocks to the SYR has no significant impact on SLR. Since mid-2015, both risks are gradually increasing and as of 2018, they are at their highest levels over the last five years.
\end{abstract}

(c) 2018 Elsevier B.V. All rights reserved.

\section{Introduction}

Market liquidity, defined as the ability to trade large quantities of assets quickly at a low cost, is a crucial element for the proper functioning of financial markets and of great interest to market participants and policymakers. We have seen, over the last two decades, an extensive body of research that examines the comovement between individual asset liquidity and market-wide liquidity. Following the works of Chordia et al. (2000), Huberman and Halka (2001) and Hasbrouck and Seppi (2001), empirical studies have shown that liquidity is subject to a spillover effect influencing other assets traded in the same market. In this scheme of things, liquidity is not just the trading cost of an individual asset but also a potential systematic risk factor due to commonality

\footnotetext{
* Corresponding author.

E-mail address: ahmet.sensoy@bilkent.edu.tr (A. Sensoy).

1 Ahmet Sensoy acknowledges the French Embassy Fellowship for visiting researchers in 2018 .
}

(Pastor and Stambaugh, 2003; Acharya and Pedersen, 2005; Sadka, 2006; Korajczyk and Sadka, 2008). Therefore, analyzing the systematic liquidity risk factor is important as it might offer a clue to solving the puzzles of market dry-ups and crashes, provide more accurate signal for portfolio selections, improve market designs, and further contribute to financial stabilization policies (Sensoy, 2017).

The related literature on this subject has covered many asset classes such as equities (see above), foreign exchanges (Mancini et al., 2013; Karnaukh et al., 2015), US treasuries (Fleming, 2003; Chordia et al., 2005), US corporate bonds (Lin et al., 2011; Bao et al., 2011), and even the CDS markets (Coro et al., 2013; Mayordomo et al., 2014). However, sovereign bond markets, and particularly the European Monetary Union (EMU) sovereign bonds, have not received much attention. This is indeed surprising given the fact that the recent global financial crisis of 2007-2008 and the Eurozone debt crisis in 2012 caused deep recession, unemployment, macro-economic imbalances, and banking sector problems in the region. More importantly, these crises have revealed that 
the EMU sovereign bond markets are not immune to liquidity shortage.

Regarding the EMU sovereign bond markets, studies mostly focus on the determinants of liquidity differences across bonds, or how individual liquidity effects the corresponding bond's main characteristics. For example, Petrella and Resti (2013) show that both market factors (such as the quality difference between low and high rated bonds) and bond specific factors (duration, size) have an impact on the cross-sectional liquidity differences (see also Manganalli and Wolswijk (2009)). In a recent study, Boermans et al. (2016) find that liquidity is a significant driver of bond price volatility during the 2013 Taper Tantrum and 2015 Bund Tantrum period.

In this study, we rather focus on the systematic liquidity component of the EMU sovereign bond markets as well as its relationship with the systematic yield risk. For this purpose, we first introduce a systematic liquidity risk (SLR) index using daily bond spreads and dynamic conditional beta methodology (Bali et al., 2017) to observe its time variation. Next, we introduce a similar index (systematic yield risk, SYR) to detect the collective variation in yields of these sovereign bonds.

Earlier studies suggest that the systematic liquidity is an important determinant of an asset's expected return (Pastor and Stambaugh, 2003; Acharya and Pedersen, 2005; Korajczyk and Sadka, 2008; Brunnermeier and Pedersen, 2009) and this was also tested empirically on EMU sovereign bond prices by Jankowitsch et al. (2006) and Favero et al. (2010). ${ }^{2}$ Differently, this paper is not just interested in a bond's expected yield but focuses on the systematic yield variation across all bonds. Our proposed approach will, therefore, bring a fresh look to the subject, and have important policy implications for these markets.

Our findings show that both types of risk are strongly positively correlated, which typically supports the theoretical approach on an asset's liquidity-return spiral by Brunnermeier and Pedersen (2009) at the aggregate market level. Vector auto-regression and generalized impulse response analysis reveal that shocks to the SLR has significant impact on SYR lasting up to 5 days, whereas shocks to the SYR has no significant impact on SLR, emphasizing the increased importance of proper liquidity management in the EMU sovereign bond markets in the last decade. Finally, since mid-2015, both risks are gradually increasing and as of 2018, they are at their highest levels of the last five years, suggesting that policymakers, public debt managers, and market participants should be alerted and on guard for the potential upcoming consequences in these markets.

The rest of our paper is structured as follows. Section 2 presents the data and reports the empirical results. Section 3 provides some concluding remarks.

\section{Data and results}

We consider daily 10-year benchmark government bond's ask and bid yields for a sample of eleven countries to carry out our empirical analysis. These countries include Austria, Belgium, Finland, France, Germany, Greece, Italy, Ireland, Netherlands, Portugal, and Spain. The data are obtained from Bloomberg. The sample spans a time period from May 1, 2013 until Feb 6, 2018. The sample start date was chosen to get bid and ask yield data for all countries in our study. It is worth noting that before this date, there are many missing observations for some of the sample countries.

\footnotetext{
2 However, these studies find conflicting results. The former study finds very limited liquidity effect on bond prices and suggests that other effects, such as credit risk, are important driving factors of bond price differences in the cross-section. On the other hand, the latter study states that bond price differentials increase with liquidity risk.
}

\subsection{The model and the results}

Inspired by the work of Chordia et al. (2000), we start with the following market models to examine the systematic yield and liquidity risks in EMU:

$D Y_{i, t}=\alpha_{i}+\beta_{i} D Y_{M, t}+\varepsilon_{i, t}$

$D L_{i, t}=\tilde{\alpha}_{i}+\tilde{\beta}_{i} D L_{M, t}+\tilde{\varepsilon}_{i, t}$

where $L_{i, t}$ is a general notation to denote the measure of an individual liquidity (bid-ask spread) for bond $i$ on day $t ; L_{M, t}$ is equally-weighted cross-sectional average of the liquidity variable for all bonds on day $t$ excluding bond $i$. $Y_{M, t}$ is equally-weighted cross-sectional average of individual yields for all bonds on day $t$ excluding bond $i$. The operator $D$ stands for the daily first difference wherever it is used. Exclusion of the individual bond variables in constructing the aggregate variables is to remove the effect of bond $i$ 's own variation on the market average and remove the constraint that the cross-sectional average of the betas has to be unity. Finally, $D Y_{i, t}$ and $D L_{i, t}$ are winsorized at $2.5 \%$ levels on both sides for each $i$ to remove the outlier effect in our analysis.

Unlike the classical approaches, the estimations above are performed by the state of the art methodology of Dynamic Conditional Beta (DCB) proposed by Bali et al. (2017), which allows us to estimate a time-varying yield and liquidity beta for each bond $i$ without consuming any initial data unlike in the case of rolling window beta estimations. ${ }^{3}$ With these estimations, we end up with a liquidity beta $\left(\tilde{\beta}_{i, t}\right)$ and yield beta $\left(\beta_{i, t}\right)$ value for each day $t$ and for each bond $i$.

After estimating the time-varying yield and liquidity betas in Eqs. (1) and (2), we calculate the median of betas for yield and liquidity on each day for the whole sample countries. While the former is a proxy for systematic yield risk (SYR), the latter is an indicator of systematic liquidity risk (SLR)., ${ }^{4,5}$

Fig. 1 displays the time-varying SYR and SLR measures. The sub-figure on the upper-left corner shows the actual dynamic median beta values for yield and liquidity. To make them easily comparable, we add the normalized version of these risk measures that have zero means and unit variances, which are displayed on the upper-right corner of Fig. 1. Finally, we apply Hodrick and Prescott (1997) filter to our normalized risk measures to eliminate noise and extract the trends in both types of risks in order to focus on the big picture. ${ }^{6}$

At the first sight, we notice that there is the strong similarity in the long term trends of the SYR and SLR. The correlation level among the first differences of these risk trends is 0.50 and statistically significant. The two risks increased significantly between May 2013 to June 2014, and then felt down to the lowest level in the third and fourth quarters of 2015. They then rose sharply to reach extremely high level in October 2017.

Specifically, a deeper investigation of the smoothed risk trends shows that the SYR and SLR indices increase for the EMU bond

\footnotetext{
3 It also saves us from picking window length which is usually subject to criticism in empirical studies. See Appendix for the DCB methodology.

4 This approach was previously used by Sensoy (2016) on equity markets to measure systematic return risk.

5 Taking the mean of betas produces similar results.

6 This filtering uses ideas related to the decomposition of time series: Let $y_{t}$ for $t=1,2, \ldots, T$ denote the logarithms of a time series variable. The series $y_{t}$ is made up of a trend component, denoted by $\tau$ and noise $c$ such that $y_{t}=\tau_{t}+c_{t}$. Given an adequately chosen positive $\lambda$, there is a trend component that solves $\min _{\tau}\left(\sum_{t=1}^{T}\left(y_{t}-\tau_{t}\right)^{2}+\lambda \sum_{t=2}^{T-1}\left[\left(\tau_{t+1}-\tau_{t}\right)-\left(\tau_{t}-\tau_{t-1}\right)\right]^{2}\right)$. The first term of the equation is the sum of the squared deviations $d_{t}=y_{t}-\tau_{t}$ which penalizes the noise. The second term is a multiple $\lambda$ of the sum of the squares of the trend component's second differences. This second term penalizes variations in the growth rate of the trend component.
} 

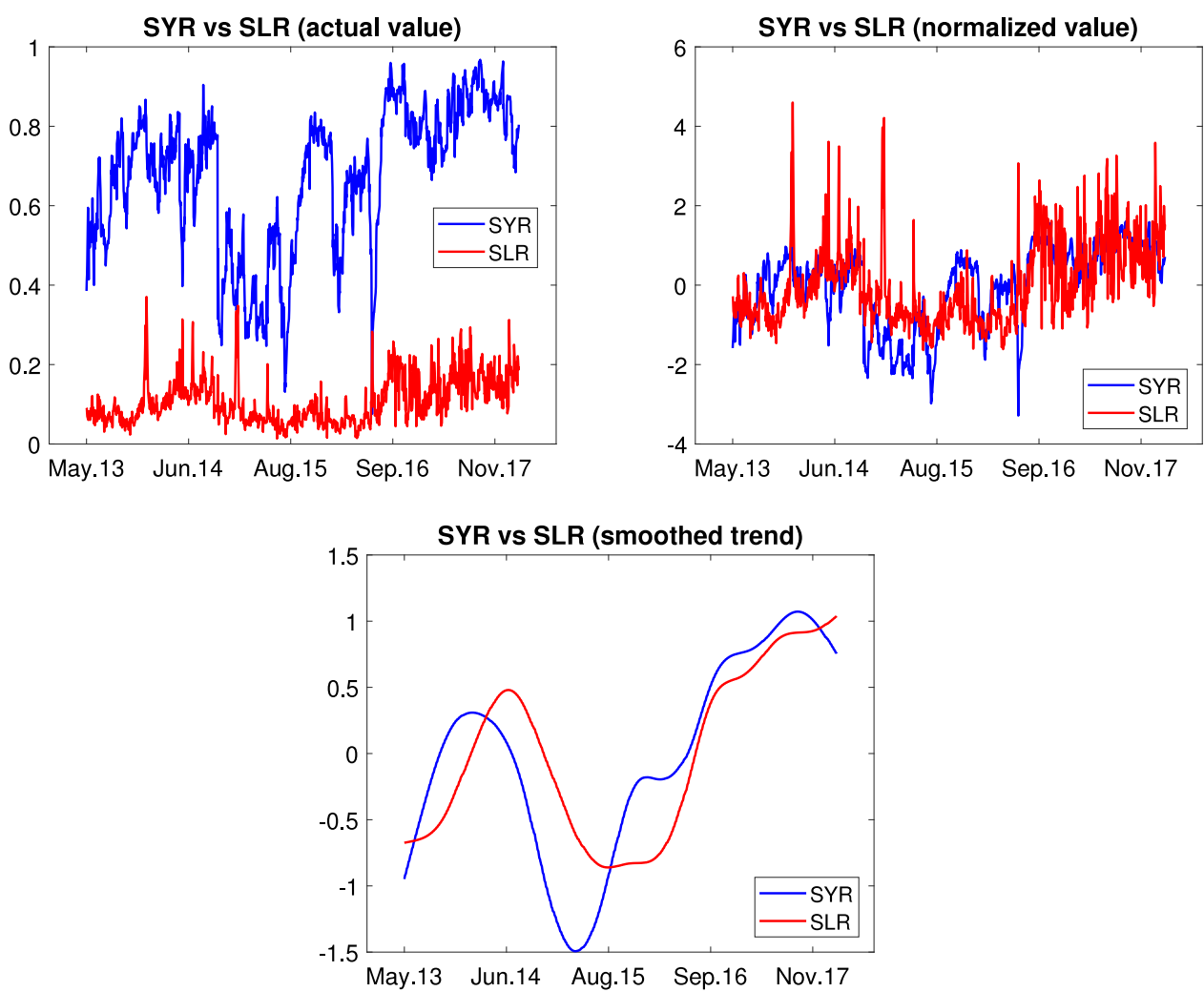

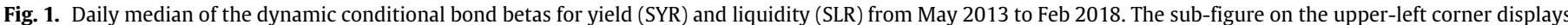

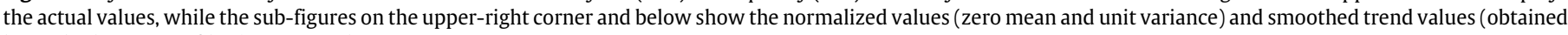
by Hodrick-Prescott filter) respectively.

markets during 2013-2014 seems to be mostly due to the formal announcement of the "Fed tapering" by the Chairman of the Federal Reserve, Ben Bernanke, on May 22, 2013. It is likely that this announcement may have triggered a flight-to-quality mechanism (from emerging to developed markets) in the global arena. Although some of the sample countries in our analysis were still struggling with serious debt problems in the announcement time, their longtime successful fiscal history compared to the emerging markets would make them more investable in times of global liquidity shortage. Indeed, the massive capital outflows from emerging markets during this period have led to the devaluation of currencies of Chile, India, Brazil, Turkey, South Africa and Indonesia with a range from $10 \%$ to $26 \%$ in 2013 . In the meantime, bond yields of EMU members (even the ones with debt problems) significantly shrank. This new economic situation pushes all yields of EMU members in the same direction and also narrows the overall spreads for around a year, signaling an increase in liquidity and yield commonality (i.e., the observed increase in SLR and SYR). Thus, a potential consequence is that a shock to the system would let the inflow capitals to leave, which leads to an all-around decrease (increase) in liquidity (yield) in the region.

However, things have turned around mid 2014. Despite the apparent improvement in Greece's situation (due to bailout program and increased capital inflow), it was understood that a quick resolution to the crisis was not to be. In June 2014, the ECB cut its deposit rate to $-0.1 \%$ in an effort to trigger lending. This was the first time that a major central bank has charged depositors a fee for holding cash in excess of legally mandated reserves. In September 2014 , the deposit rate was cut again to $-0.2 \%$. The lack of faith in the region for future prospects led to the segmentation of EMU bond markets again into reliable (strong fiscal conditions) and not-so-reliable countries (struggling with debt problems). Such a segmentation breaks the synchronicity of the yield and liquidity movements in the EMU bond markets, therefore SYR and SLR tend to decrease during this period.

The last major pattern is probably the most striking one. Since the middle of 2015, both SYR and SLR start to increase, and this trend continues gradually ever since then, reaching up to their highest levels within five years of whole sample period. On top of the potential reasons is the liquidity decline fear due to the implementation of the EU Markets in Financial Instruments Directive (MIFID II) which aims at enhancing market transparency and investor protection particularly through increased supervision of financial services firms, increased regulation on traded securities, and OTC trading restrictions. Consequently, both systematic liquidity and yield risk could rise as a result of transparency rules, reduced inventories for market makers and dealers, and increased capital requirements for dealers.

\subsection{Impulse response analysis}

The influence of both types of risks on each other has been long of great interest to policymakers and regulators. To better understand the dynamics between SYR and SLR, we proceed with an unrestricted Vector Autoregression Model $(\operatorname{VAR}(p))$ applied on our risk measures. The daily percentage changes of (normalized) SYR and SLR are used in the estimation process (optimal lag selection $p$ is found to be four in this case). We employ the generalized impulse response functions (GIRFs) to investigate how the shocks are transmitted from one systematic risk to another. The estimated parameters of the VAR model are given in Table 1 and the impulse responses are given in Fig. 2. The VAR coefficients in Table 1 show the strong explanatory power of SLR on SYR. On the other hand, the interesting thing is the poor explanatory power of the lagged SYR

7 Sensoy et al. (2018) show this segmentation clearly using network analysis. 

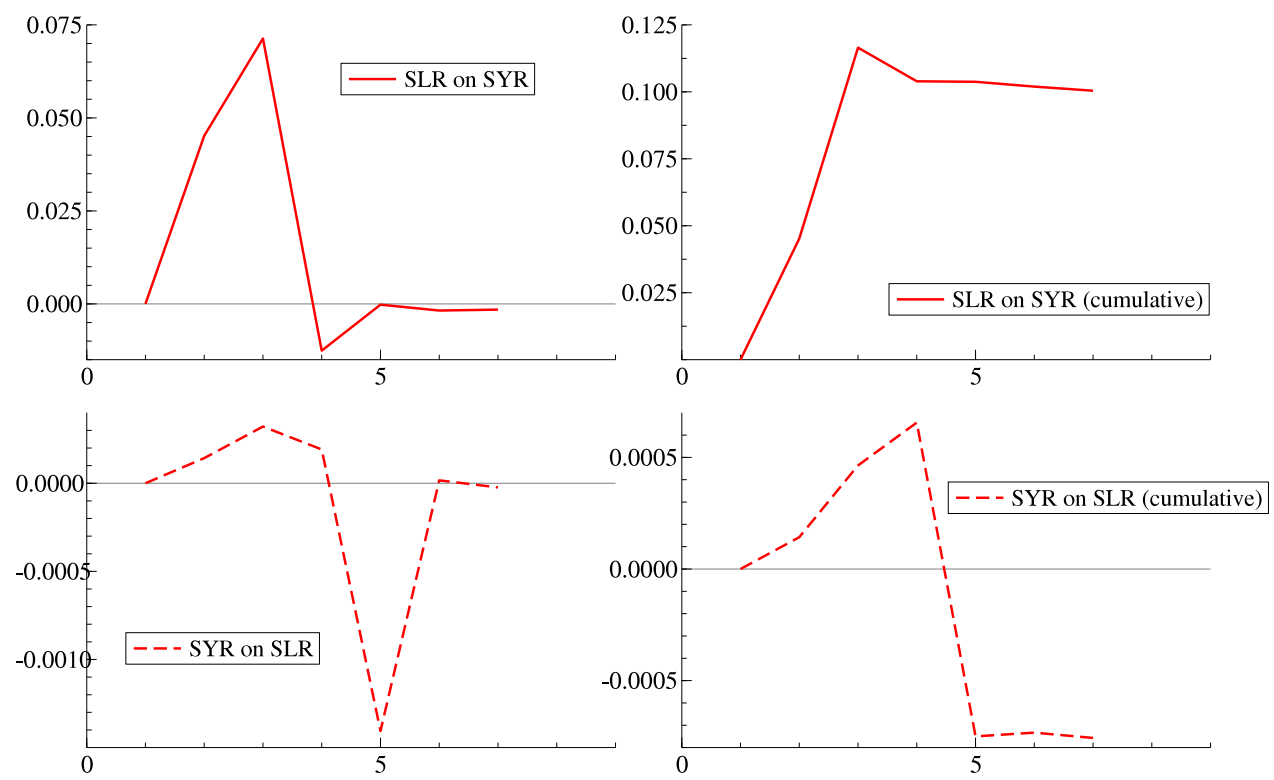

Fig. 2. Generalized impulse responses of shocks to the systematic yield risk (SYR) and systematic liquidity risk (SLR) on each other. Dashed lines denote insignificance.

Table 1

Parameter estimates for VAR(4) using normalized systematic risk measures SYR and SLR.

\begin{tabular}{llllll}
\hline & $S Y R_{t}$ & & & \multicolumn{2}{l}{$S L R_{t}$} \\
\cline { 2 - 3 } \cline { 5 - 6 } & Coefficient & $p$-value & & Coefficient & $p$-value \\
\hline$S Y R_{t-1}$ & $-0,0146^{* * *}$ & 0.000 & & 0.0452 & 0.359 \\
$S Y R_{t-2}$ & 0.0151 & 0.235 & & 0.0719 & 0.396 \\
$S Y R_{t-3}$ & $-0.0065^{* *}$ & 0.013 & & -0.0119 & 0.537 \\
$S Y R_{t-4}$ & $-0,0224^{* * *}$ & 0.000 & & -0.0007 & 0.946 \\
$S L R_{t-1}$ & $0.0001^{*}$ & 0.056 & & -0.0001 & 0.807 \\
$S L R_{t-2}$ & $0.0003^{* * *}$ & 0.000 & & $-0.0050^{* * *}$ & 0.000 \\
$S L R_{t-3}$ & $0.0002^{* * *}$ & 0.000 & & -0.0020 & 0.249 \\
$S L R_{t-4}$ & $-0.0014^{* * *}$ & 0.000 & & -0.0009 & 0.193 \\
Constant & 0.3769 & 0.153 & & -3.0808 & 0.3545 \\
\hline
\end{tabular}

on SLR. According to the impulse response analysis, the impact of shocks to SLR on SYR is positive and significant, and lasts up to 5 days, whereas shocks to SYR have no significant impact on SLR.

\subsection{Relation with other financial risk indicators}

After understanding the relation between the systematic yield and liquidity risks in the EMU sovereign bond markets, we next analyze how these risks are related to other major financial risk indicators in the world, namely; VIX, V2X, FCONUS and FCONEU. VIX and V2X are the implied volatility indices of the US and eurozone equity markets respectively, and they are referred to as financial fear gauges in the corresponding regions. On the other hand, FCONUS and FCONEU are the financial conditions indices of US and eurozone. These indices are calculated and disseminated by Bloomberg.

At this stage, we simply analyze how these major risk indices are correlated with the systematic yield and liquidity risks in the EMU sovereign bond markets. In Table 2, the first four rows show the unconditional correlation levels (and the corresponding $p$-values) between the daily changes in the normalized SYR/SLR measures and the selected financial risk indicators. ${ }^{8}$

\footnotetext{
8 Since we are dealing with normalized series, we take the first differences (instead of the usual log-returns or percentage returns) as the daily changes in the considered variables.
}

Table 2

Correlation between SYR-SLR and other financial indicators.

\begin{tabular}{lllll}
\hline & VIX & V2X & FCONUS & FCONEU \\
\hline SYR & 0.008 & $0.052^{*}$ & -0.011 & $-0.058^{* *}$ \\
$p$-value & $(0.782)$ & $(0.075)$ & $(0.709)$ & $(0.046)$ \\
SLR & 0.023 & 0.036 & -0.005 & -0.036 \\
$p$-value & $(0.434)$ & $(0.215)$ & $(0.873)$ & $(0.223)$ \\
SYR $($ CCC $)$ & 0.017 & 0.028 & -0.023 & $-0.043^{*}$ \\
$p$-value & $(0.381)$ & $(0.171)$ & $(0.410)$ & $(0.061)$ \\
SLR (CCC) & 0.004 & 0.025 & -0.011 & -0.033 \\
$p$-value & $(0.733)$ & $(0.312)$ & $(0.480)$ & $(0.226)$ \\
\hline
\end{tabular}

The values in the parentheses are $p$-values. ${ }^{*},{ }^{* *}$ and ${ }^{* * *}$ denote $10 \%, 5 \%$ and $1 \%$ significance level. CCC denotes constant conditional correlation model of Bollerslev (1990).

The finding shows that SYR is weakly, however significantly correlated with V2X and FCONEU. Accordingly, as fear in the eurozone equity markets increases, so does the SYR in the EMU sovereign bond markets. Similarly, an improvement in the financial conditions of the eurozone is accompanied by a decrease in the SYR. However, neither fear in the US equity market nor the financial conditions in the US are significantly related to SYR. Interestingly, SLR is not significantly correlated with any of the selected financial risk indicators. Considering SLR's importance that was found in the previous analysis of Section 2.2, market participants should pay extra attention to this variable since it cannot be anticipated by the other main risk indicators.

Finally, one might concern that considered series might exhibit ARCH effect which might influence the correlation levels, hence the previous findings are not valid. To deal with this concern, we also estimate the constant conditional correlations between the same return series using the model of Bollerslev (1990). In doing so, we use a standard $\operatorname{GARCH}(1,1)$ model for the univariate volatility of the considered variables. Correlation levels and the corresponding $p$-values are given in the last four rows of the Table 2 . As evident from the table, main conclusion remains the same.

\section{Conclusion}

Public concerns have substantially increased over recent years when the market liquidity in the secondary sovereign bonds worsen. ${ }^{9}$ Moreover, liquidity stresses generally lead to tensions

9 See, OECD Sovereign Borrowing Outlook, https://doi.org/10.1787/23060476. 
in the financial markets and increase sovereign bond risks. It is equally well documented that the global financial crisis and the Eurozone debt crisis have negative impacts on the EMU sovereign market liquidity. In this paper, we shift our focus on whether changes in market liquidity contain signals on the evolution of sovereign bond market risks. Accordingly, we constructed, a systematic liquidity risk (SLR) index and an analogous systematic yield risk index (SYR) through the use of the daily 10-year benchmark government bond spreads in the EMU and the dynamic conditional beta methodology proposed by Bali et al. (2017). These indices allow us to capture time variations in both types of risk as well as analyze their interactions.

We find a positive relationship between the two types of risks under consideration over the period from 1 May 2013 until 6 Feb 2018 , as well as their highest levels since mid-2015. With respect to the VAR estimation and impulse response analysis, there is also evidence of a significant effect of SLR on SYR, but not in the other way around. Taken together, our results suggest that market participants and particularly public debt managers should have to closely follow the changing patterns of the systematic liquidity risk to implement proper liquidity management in order to prevent adverse effects from rising liquidity risks.

\section{Appendix. Dynamic conditional beta}

This section explains how the dynamic conditional beta is obtained. The case for the yields is similar. We start with the following

$D L_{t}=\mu+\epsilon_{t}$

where $D L_{t}=\left[\begin{array}{ll}D L_{i, t} & D L_{M, t}\end{array}\right]^{\prime}$ is the vector of daily liquidity changes (as the first difference) in the individual bond $i$ and the corresponding market $M, \mu$ is a vector of constants, and $\epsilon_{t}=\left[\begin{array}{ll}\epsilon_{i, t} & \epsilon_{M, t}\end{array}\right]^{\prime}$ is the vector of residuals.

In the next step, we obtain the conditional volatilities $h_{t}$ from the univariate GJR-GARCH $(1,1)$ process.

$$
\begin{array}{r}
h_{i, t}^{2}=\omega_{i}+\left(\alpha_{i}+\gamma_{i} I_{\epsilon_{i, t-1}<0}\right) \epsilon_{i, t-1}^{2}+\beta_{i} h_{i, t-1}^{2} \\
h_{M, t}^{2}=\omega_{M}+\left(\alpha_{M}+\gamma_{M} I_{\epsilon_{M, t-1}<0}\right) \epsilon_{M, t-1}^{2}+\beta_{M} h_{M, t-1}^{2}
\end{array}
$$

In this setup, $E_{t-1}\left[\epsilon_{t}\right]=0$ and $E_{t-1}\left[\epsilon_{t} \epsilon_{t}^{\prime}\right]=H_{t}$, where $E_{t}[\cdot]$ is the conditional expectation on $\epsilon_{t}, \epsilon_{t-1}, \ldots$. The conditional covariance matrix $H_{t}$ can be written as

$H_{t}=D_{t}^{1 / 2} R_{t} D_{t}^{1 / 2}$

where $R_{t}$ is the conditional correlation matrix and the diagonal matrix of the conditional variances is given by $D_{t}=\operatorname{diag}\left(h_{i, t}, h_{M, t}\right)$. Engle (2002) models the right hand side of Eq. (A.3) rather than $H_{t}$ directly and proposes the dynamic correlation structure

$$
\begin{array}{r}
R_{t}=\left\{Q_{t}^{*}\right\}^{-1 / 2} Q_{t}\left\{Q_{t}^{*}\right\}^{-1 / 2}, \\
Q_{t}=(1-a-b) S+a u_{t-1} u_{t-1}^{\prime}+b Q_{t-1},
\end{array}
$$

where $Q_{t}$ is the dynamic covariance driving process, $u_{t}=$ $\left[\begin{array}{ll}u_{i, t} & u_{M, t}\end{array}\right]^{\prime}$ with $u_{i, t}$ and $u_{M, t}$ are the transformed residuals; i.e., $u_{i, t}=\epsilon_{i, t} / h_{i, t}$ and $u_{M, t}=\epsilon_{M, t} / h_{M, t} ; S \equiv E\left[u_{t} u_{t}^{\prime}\right]$ is the $n \times n$ unconditional covariance matrix of $u_{t} ; Q_{t}^{*}=\operatorname{diag}\left\{Q_{t}\right\}$ and $a, b$ are non-negative scalars satisfying $a+b<1$. The final estimation is performed by maximizing the joint log-likelihood of the model given by

$$
\begin{array}{r}
\mathbb{L}=-\frac{1}{2} \sum_{t=1}^{T}\left(n \ln (2 \pi)+\ln \left|D_{t}\right|+\epsilon_{t}^{\prime} D_{t}^{-1} \epsilon_{t}\right) \\
-\frac{1}{2} \sum_{t=1}^{T}\left(\ln \left|R_{t}\right|+u_{t}^{\prime} R_{t}^{-1} u_{t}-u_{t}^{\prime} u_{t}\right)
\end{array}
$$

and the resulting model is called DCC. We estimate the timevarying conditional covariance matrix, giving us the dynamic covariance between bond liquidity $L_{i}$ and the market liquidity $L_{M}$, and also the dynamic variance of the market liquidity $L_{M}$. Finally, simple division yields to the time-varying liquidity betas based on the mean-reverting DCC model of Engle (2002). For recent applications of dynamic conditional beta on financial markets, see Bali and Engle (2010) and Engle et al. (2015).

\section{References}

Acharya, V., Pedersen, L.H., 2005. Asset pricing with liquidity risk. J. Financ. Econ. 77, 375-410.

Bali, T.G., Engle, R.F., 2010. The intertemporal capital asset pricing model with dynamic conditional correlations. J. Monet. Econ. 57, 377-390.

Bali, T.G., Engle, R.F., Tang, Y., 2017. Dynamic conditional beta is alive and well in the cross-section of daily stock returns. Manag. Sci. 63, 3760-3779.

Bao, J., Pan, J., Wang, J., 2011. The illiquidity of corporate bonds. J. Finance 66, $911-$ 946.

Boermans, B.A., Frost, J., Bisschop, S.S., 2016. European bond markets: Do illiquidity and concentration aggravate price shocks? Econom. Lett. 141, 143-146.

Bollerslev, T., 1990. Modelling the coherence in short-run nominal exchange rates: A multivariate generalized ARCH model. Rev. Econ. Statist. 72, 498-505.

Brunnermeier, M.K., Pedersen, L.H., 2009. Market liquidity and funding liquidity. Rev. Financ. Stud. 22, 2201-2238.

Chordia, T., Roll, R., Subrahmanyam, A., 2000. Commonality in liquidity. J. Financ. Econ. 56, 3-28.

Chordia, T., Sarkar, A., Subrahmanyam, A., 2005. An empirical analysis of stock and bond market liquidity. Rev. Financ. Stud. 18, 85-129.

Coro, F., Dufour, A., Varotto, S., 2013. Credit and liquidity components of corporate CDS spreads. J. Bank. Finance 37, 5511-5525.

Engle, R.F., 2002. Dynamic conditional correlation: a simple class of multivariate generalized autoregressive conditional heteroskedasticity models. J. Bus. Econom. Statist. 20, 339-350.

Engle, R.F., Jondeau, E., Rockinger, M., 2015. Systemic risk in Europe. Rev. Finance 19, 145-190.

Favero, C., Pagano, M., von Thadden, 2010. How does liquidity affect government bond yields? J. Financ. Quant. Anal. 45, 107-134.

Fleming, M.J., 2003. Measuring treasury market liquidity. NY Fed Econ. Policy Rev 9, 83-108.

Hasbrouck, J., Seppi, D.J., 2001. Common factors in prices, order flows, and liquidity J. Financ. Econ. 59, 383-411.

Hodrick, R., Prescott, E.C., 1997. Postwar U.S. business cycles: An empirical investigation. J. Money Credit Bank. 29, 1-16.

Huberman, G., Halka, D., 2001. Systematic liquidity. J. Financ. Res. 24, 161-178.

Jankowitsch, R., Mosenbacher, H., Pichler, S., 2006. Measuring the liquidity impact on EMU government bond prices. Eur. J. Finance 12, 153-169.

Karnaukh, N., Ranaldo, A., Soderlind, P., 2015. Understanding FX liquidity. Rev. Financ. Stud. 28, 3073-3108.

Korajczyk, R.A., Sadka, R., 2008. Pricing the commonality across alternative measures of liquidity. J. Financ. Econ. 87, 45-72.

Lin, H., Wang, J., Wu, C., 2011. Liquidity risk and expected corporate bond returns J. Financ. Econ. 99, 628-650.

Mancini, L., Ranaldo, A., Wrampelmeyer, J., 2013. Liquidity in the foreign exchange market: Measurement, commonality, and risk premiums. J. Finance 68, 18051841

Manganalli, S., Wolswijk, G., 2009. What drives spreads in the euro area government bond market? Econ. Policy 24, 191-240.

Mayordomo, S., Rodriguez-Moreno, M., Pena, J.I., 2014. Liquidity commonalities in the corporate CDS market around the 2007-2012 financial crisis. Int. Rev. Econ. Finance 31, 171-192.

Pastor, L., Stambaugh, R., 2003. Liquidity risk and expected stock returns. J. Political Econ. 113, 642-685.

Petrella, G., Resti, A., 2013. What drives the liquidity of eurozone sovereign bonds? GRETA Working Paper Series.

Sadka, R., 2006. Momentum and post-earnings announcement drift anomalies: The role of liquidity risk. J. Financ. Econ. 80, 309-349.

Sensoy, A., 2016. Systematic risk in conventional and Islamic equity markets. Int Rev. Finance 16, 457-466.

Sensoy, A., 2017. Firm size, ownership structure, and systematic liquidity risk: The case of an emerging market. J. Financ. Stab. 31, 62-80.

Sensoy, A., Nguyen, D.K., Rostom, A., Hacihasanoglu, E., 2018. Dynamic integration and network structure of the EMU sovereign bond markets. Ann. Oper. Res. URL https://dx.doi.org/10.1007/s10479-018-2831-1. 